\title{
When the work of academic developers branches out: Considering trade-offs as an inherent part of practice
}

\author{
LISE TOFT HENRIKSEN ${ }^{1 * *}$ (]) and LEA STÆR ESKESEN ${ }^{2 * * *}$ (]) \\ ${ }^{1}$ University of Oslo, Oslo, Norway \\ ${ }^{2}$ University of Southern Denmark, Odense, Denmark
}

\section{THEMATIC ARTICLE}

Received: October 11, 2020 • Accepted: May 18, 2021

Published online: July 30, 2021

(C) 2021 The Author(s)

\begin{abstract}
This article investigates how introducing new activities to the practice of academic development can influence and challenge both the academic developers and the Centres for Teaching and Learning (CTL). By applying Wenger's (1998) Communities of Practice, (part of) the practice of the academic developers is conceptualised as exercising collegial relationships. An empirical investigation in the context of a CTL at a Scandinavian university illustrates possibilities for learning and growth of the CTL, as well as how exercising collegial relationships is being challenged when the work of the academic developers branches out. The article concludes that trade-offs are not only an inherent part of practice, but also an aspect of practice that calls for continuous attention.
\end{abstract}

\section{KEYWORDS}

Collegial relationships, Centres for Teaching and Learning, Communities of Practice, Academic development

\footnotetext{
* Corresponding author. E-mail: lea.staer@gmail.com

** Both authors contributed equally.
} 


\section{INTRODUCTION}

The Centres for Teaching and Learning (CTLs) have been given greater attention and more prominent and clearer positions at the universities (Sugrue, Englund, Solbrekke, \& Fossland, 2018, p. 2343). One reason for this development is the continuous focus on how academic development can support different organisational challenges that the universities are facing, often brought on by national reforms in higher education (Gosling, 1996; Havnes \& Stensaker, 2006; Stensaker, van der Vaart, Solbrekke, \& Wittek, 2017). Concurrently within the CTLs, academic developers (ADs) support both academic staff and the leadership in matters of educational development. They experience a growing complexity in the tasks and responsibilities they face, which also includes engaging in new activities at different levels of the institution (Solbrekke, Sugrue, \& Sutphen, 2020; Sugrue et al., 2018). Solbrekke and Fremstad (2018) highlight a related aspect of the ADs' practices: leadership expectations of the ADs' contribution in the institution can be seen as the institutional leaderships' trust in the ADs, which results in greater influence on the institutional level. Meanwhile, the collegial relationships and trust between ADs and academic staff may as a consequence weaken (Solbrekke \& Fremstad, 2018, p. 241). Therefore, in the context of this journal, we argue that exploring the 'big ideas' behind practices adopted by CTLs calls for a closer investigation of how new activities introduced to the practice of academic development influences and challenges both the academic developers and the CTLs. We propose that such an investigation implies being sensitive towards the everyday practice of the academic developer, and what constitutes meaningful relationships with academic staff. As this article exemplifies, conceptualising a part of the ADs' practice as exercising collegial relationships can be helpful for these purposes.

\section{Applying 'communities of practice' as a theoretical lens}

A way to focus on the everyday practice of the ADs and their interactions with other actors in the institution is to consider the ADs as a specific community of practice framed by the CTL and placed in a constellation of practices within the university. A community of practice (Wenger, 1998) can be described as a social group that over time builds shared norms, rules, routines, knowledge, understandings, and artefacts that constitute the boundaries of the community and gives its members a certain sense of identity (p. 73). The community defines what it means to be a competent participant, that is, what knowledge, understandings, and actions can be accepted and recognised as relevant (Wenger, 1998, p. 137). These shared beliefs and understandings move the ADs to orient themselves in specific directions or to consider specific conditions and relations to be obvious (Sfard \& Prusak, 2005; Wenger, 1998, p. 239). However, as we will exemplify below, the same community can also hold different inconsistent, contradictory or even conflicting perspectives and orientations (Wenger, 1998, p. 83). What defines the community of practice is subject to constant re-negotiation by its members, who continuously bring in new understandings and experiences. These new contributions create grounds for learning, and they have the potential to move the communities' boundaries, creating new opportunities for involvement and interaction. Hence, learning is at the essence of development and growth of the community (Farnsworth, Kleanthous, \& Wenger-Trayner, 2016; Wenger, 2000, p. 233, p. 153).

As already stated, the ADs increasingly collaborate with a range of different actors and on different levels of the institution. When conceptualising the ADs in Wenger's social learning 
theory, the ADs can be described as brokers who translate and negotiate higher education pedagogy into other parts of the organisation by working in the boundaries between different communities (Solbrekke \& Fremstad, 2018; Wenger, 1998, p. 109). These interactions are called boundary interactions (Wenger, 1998, p. 112). To be able to negotiate meaningfully with other communities requires that participants from these communities perceive the brokers' presence as legitimate. As Wenger explains: "Brokering knowledge is delicate. It requires enough legitimacy to be listened to and enough distance to bring something really new" (Wenger, 2000, p. 236). To simply agree with the other participant will not move them to learn anything new about higher education pedagogy, but to stray too far away from their existing beliefs will make the negotiation meaningless to the participants. At the same time, these constantly re-negotiated and re-constituted relationships are only constructive insofar both parties agree on the premises of the relationships and the interactions (Wenger, 2000, p. 236). This makes brokering an act of balancing between different agendas and continuously sensing the direction of the interaction.

Following the example given by Solbrekke and Fremstad (2018), the growing complexity in tasks and responsibilities makes it increasingly challenging to navigate this balancing act. However, as also implied by Solbrekke and Fremstad (2018) and proposed by Wenger (1998), trade-offs are an inherent aspect of practice. Whether it comes to giving up old norms and routines to make way for new, or engaging in some relationships that weakens others, trade-offs are a part of the growth and development for any community (Wenger, 1998. p. 173-187).

\section{Research question}

With this in mind, this study uses Wenger's (1998) definitions of broker and boundaries as a theoretical lens to investigate a specific case, in which a CTL's engagement in new activities implies a trade-off that creates both new learning opportunities for the community and challenges the academic developers' meaningful interactions with academic staff. The question becomes:

1. How can new activities become a lever for re-negotiation and learning in the practice of academic development and

2. at the same time pose a challenge for meaningful interactions?

\section{METHOD AND EMPIRICAL DATA}

We draw on empirical data collected at a CTL at a major Scandinavian university, where the CTL recently started engaging in programme evaluations. Using interview extracts from four single-person interviews with ADs, talking about their academic development practices, the article captures and frames a specific situation, in which the trade-off between sustaining meaningful collegial relationships in consultations and courses and engaging in these evaluation activities become exposed.

Programme evaluations in this context are regarded as an activity brought on by external influence in the institution. The national legislation concerning the educational enterprise at the universities has meant that the university in question has adopted periodic programme evaluations as part of the institution's Quality Assurance System. The faculty responsible for a given study programme appoints a panel, who will perform an external evaluation as required by the 
Quality Assurance System. The CTL in question is on request from the faculties involved in the panel's work, and this brings on a new activity for the ADs that not only expands their area of work, but, as this article illustrates, also introduces a new and challenging premise to the boundary interaction.

The interviews have been analysed using a thematic approach as described by Braun and Clarke (2006), in which the transcribed data is systematically coded and gathered into patterns and themes, based on the data, theory, and existing literature. During the interviews and in the following analysis, we have had a particular focus on tasks that require boundary interaction that is, the part of practice that is concerned with negotiating pedagogical knowledge and understanding into other parts of the organisation. Furthermore, we have focused on inconsistencies and conflicts to highlight those processes, in which negotiation both internal to the community and in boundary interactions meet resistance and requires the ADs to legitimise their presence and positions (Wenger, 1998, p. 83).

\section{Meaningful boundary interactions and collegial relationships}

First, to present what constitutes meaningful boundary interactions in the practice of ADs in our empirical context, we define a broker as someone who works at the boundaries between communities by "introducing into a practice elements of another" (Wenger, 1998. p. 109). The boundaries of a community of practice are rather fluid and become obvious mostly when crossed (Wenger, 1998, p. 104). For example, for academic staff in the field of Physics, discussing pedagogical issues can create the experience of having entered a world of new terms and practices that are difficult to understand and comprehend. These boundary interactions thus expose the participative parties to foreign competences and create a certain kind of learning process. A process that, to be constructive, requires sensitivity towards the differences in perspectives as well as establishing a common ground (Farnsworth et al., 2016, p. 233). Boundaries hereby connect different communities of practice, and ADs as brokers help create continuities and meaningful interactions across these connecting boundaries (Wenger, 1998, p. 109).

Moving on to applying this theoretical lens to the CTL in question, the objective to facilitate processes of "translation, coordination, and alignment between perspectives" (Wenger, 1998, p. 109) is apparent in the ADs' understanding of their practice. When teaching pedagogic courses or carrying out consultations, the ADs describe their task as one of bringing together insights from the local academics (teachers) with the ADs' own pedagogical insight. As one AD state:

We consider it a premise that there is a collaboration between us as academic developers and the local academics, because we believe that it leads to the best outcomes when we manage to unite their academic skills and understandings of the academic environment with our pedagogical insights. (AD 1)

The unification of the academics' perspectives and the ADs' pedagogical knowledge becomes the premise that makes the boundary interaction meaningful to both parties. What creates a meaningful interaction is thus when the $\mathrm{AD}$ manages the balancing act of brokering, basing the pedagogical activity on the academic staff s understandings, whilst simultaneously introducing pedagogical knowledge into the reflections of these understandings.

Turning to our empirical case, we see such an example of brokering when an AD plans and conducts pedagogical courses for an academic community in close cooperation with teachers from the community in question. By ensuring that the content of the course stays sufficiently 
close to established beliefs and understandings of the academic community, the $\mathrm{AD}$ gains legitimacy to be present at the boundary, which in turn is the premise of introducing elements of the pedagogical practice into the teaching community (Wenger, 1998. p. 109). As we see in the extract above, from the perspective of the $\mathrm{AD}$ this also means ensuring the best long-term outcomes. This specific way of ensuring and sustaining meaningful interactions and being a broker can be viewed as one of the important and uncontested understandings (Wenger, 1998. p. 73) that the CTL base their practice upon. A part of practice that we conceptualise as exercising collegial relationships.

Another aspect of exercising collegial relationships shows in consultations. Consultations are often based on an issue that is defined and problematised by the academic staff or the department who seek out the consultation. This definition is an important starting point, but, as one $\mathrm{AD}$ explains, the issue may need to be qualified with a pedagogical reframing. The $\mathrm{AD}$ is at one point approached by teachers who want to try out 'flipped classroom', and thus ask for help with a video production to support the course.

Then we start talking, and it becomes obvious that perhaps it's not video production as such, because they are really considering the whole thing, you know? Considering how to assemble the whole learning design, right? And then we engage in a dialogue to reformulate the issue at hand. But what we [the $A D s$ ] are really attentive to is that the process [of reformulating the issue at hand] safeguard their ownership of the formulation of the issue. [...] You have to help them "place the right order", but it has to be their order, that's absolutely essential. (AD 2)

Here the act of brokering means to help reformulate the issue, so it also becomes pedagogically relevant. To ensure that the interaction around that issue still remains meaningful, even though the issue is reformulated during the consultation, the $\mathrm{AD}$ must make sure that the teachers' perspectives are still prevalent in the formulations of the issue.

Exercising collegial relationships is the part of practice where the ADs act as brokers, creating constructive learning processes in the boundary interaction. Wenger states that learning at boundaries requires "commitment to suspend judgement in order to see the competence of a community in terms" (Farnsworth et al., 2016, p. 233). Exercising collegial relationships implies that the $\mathrm{AD}$ must make sure that the boundary interaction i) sustains a balanced negotiation between the teachers' perspectives and the ADs' pedagogically informed perspectives, and ii) builds on pedagogic issues and activities meaningful for the teachers. This will develop the activities and generate new definitions and solutions containing both perspectives, which will ensure the best long-term outcomes.

\section{When new activities become a lever for development in the community}

We now turn to the activities of programme evaluations. Within the group of ADs, you find discussions of possible consequences for academic development when engaging in evaluations. As one $\mathrm{AD}$ depicted from internal discussions, there are different views on possible implications:

You bring in standards and norms dictating what you think is good or not good. And it makes me think that pedagogical development is a process that to a high extent should be allowed to happen without resulting in a summative assessment.

[...] 
Good university pedagogy is about the teachers recognising what their needs are and then supporting them in this much more than telling them, here is a checklist of the things you have to do ... because my experience tells me that it very easily becomes instrumental. And it becomes very unfruitful if you only do this.

$[\ldots]$

You can engage in programme evaluations in many different ways, so I think, of course you can find a way of doing it without ending up in the extremes. ( $A D$ 1)

The reproduced aspects of working with evaluations point to how using evaluations as a pedagogical method to develop teaching practices might lead to unintended pitfalls that do not correspond well with the existing norms, ideas, and experiences of good academic development. On the other hand, doing evaluations is more than one thing and can be integrated in the repertoire of work, if done appropriately. The internal discussions on evaluation activities revolve around avoiding summative assessments and instead finding ways to incorporate evaluations that match the current practice of the community. These kinds of discussions move the community of practice in new directions (Wenger, 1998, p. 83). As previously described, programme evaluations are an activity brought on by external influence in the institution and, as indicated above, evaluations are a possible interference and a negative break away from the exciting practice. However, the empirical extract also illustrates that programme evaluations can be a lever in re-negotiating the community's repertoire (Wenger, 1998, p. 98). In this case, learning and development in the community gives new opportunities for involvement and interaction in the institution at different levels, as programme evaluations become a legitimate part of the ADs' practice (Farnsworth et al., 2016; Wenger, 1998, p. 98; Wenger, 2000, p. 233, p. 153). In other words, and as the following section exemplifies, engaging in evaluations involves trade-offs.

\section{New activities as a challenge for the meaningful interaction}

Negotiating the meaning and use of evaluations is a multi-layered process. This involves both external negotiations between the CTL and the Faculties when discussing acceptable premises for evaluations, and, as presented above, internal negotiations when members of the CTL are renegotiating whether to recognise and accept these new practices as relevant and competent (Wenger, 1998, p. 137). In this institutional context, meaningful negotiations on the institutional level to decide on the premise of the programme evaluations exist alongside a certain understanding of programme evaluations in the community of practice as a debated, but decided, activity to engage in. As expressed by an $\mathrm{AD}$ :

It has been a debate whether [the CTL] should engage in such activities. [...] [The head of the CTL] has been very involved, and now I have also taken a round [doing evaluations]. (AD 2)

Now, turning to the second question of the article, the next extract will illustrate that despite adopting evaluations as a legitimate part of the community of practice and deciding on engaging in programme evaluation on the institutional level, the CTL's engagement in programme evaluations can also pose as a challenge for the $\mathrm{AD}$. As illustrated above in the presentation of the meaningful boundary interaction, exercising collegial relationships means the unification of the academic staff s perspectives and the ADs' pedagogical knowledge to create new definitions 
of issues that are still meaningful to the local academic community. The following empirical extract, shared by an $\mathrm{AD}$, illustrates that engaging in programme evaluations can prove difficult while upholding this premise:

I was invited by a [group of academic staff] [...] and I felt a lot of resistance. [...] they had been through an evaluation, written by [the head of the CTL], haha, which had been pretty critical, right? It wasn't like they were going to cancel the programme, but they wanted to evaluate the teaching methods, and that evaluation had been pretty critical and had suggested quite, from their perspective, quite radical changes of the existing teaching practices. At that point, I had to work really hard to even gain some trust and legitimacy into that context at that meeting, haha, so I sat there very alert and tried to follow every single word that came out of these peoples' mouths to try to figure out, where can I hitch on here, what is it they really want out of this? [...] Some of them were definitely not agreeing with the premise or the conclusion in that evaluation. (AD 2)

The extract above illustrates how exercising collegial relationships is challenged. What becomes apparent in this case is that even though the $\mathrm{AD}$ manages to create a common ground and a way to move forward, the evaluative aspect introduces a challenging premise to the boundary interaction. The issue the consultation is based on is defined in advance, and in this case it means that the boundary interaction becomes established around issues that are not recognised as meaningful by the teachers involved. This compromise building and sustaining a meaningful boundary interaction. We see how it becomes difficult to ensure that the teachers' perspectives prevail in the formulations of the issue, and to concurrently engage in a process of reformulating the issue so it becomes pedagogically relevant. In short, it opposes the act of brokering pedagogical knowledge into the other community, and as follows, the possibility of ensuring the best long-term outcomes. When the possibility of exercising collegial relationships is challenged, the legitimacy of the $\mathrm{AD}$ gets compromised, and it becomes difficult to promote a learning process.

\section{CONCLUSION}

This article demonstrates how a closer investigation of practice can help explore and make visible specific trade-offs that a Centre for Teaching and Learning and the academic developers might face, when the academic development enterprise branches out and becomes intertwined in new activities at different levels of the institution. In our empirical contexts we have done so by applying Wenger's (1998) Communities of Practice as a theoretical lens and conceptualising (a part of) practice as exercising collegial relationships.

The case shows how ADs have to think and act differently in consultations if these precede evaluations. The choice of including a new evaluative activity moves the boundaries of the community, creates learning, and offers new opportunities for engagement and influence in the institution. In this case, however, the activity also interferes with the meaningful boundary interaction in unintentional ways, challenging the very premise that legitimises the ADs' positions as brokers.

Programme evaluations are of course not only a new activity, but also a specific type of activity. Though outside the scope of this article, further examination of the specific characteristics of programme evaluations would be a relevant contribution to the case. However, what we aim to do with our analysis is to argue: the practice of the AD is inextricably linked to the 
practice of the CTL, which in turn is made up of all the collective and individual work practices, choices, and strategies for academic development. This means that making choices of engaging in activities to achieve collaboration around pedagogical development in one part of the institution means making changes to the same practice in other situated contexts within the institution, regardless of the type of new activity in question. Given the complex positioning of the CTL in the institution, we consider "trade-offs" not only as an inherent part of practice, but also as an aspect of practice that calls for continuous attention.

A trade-off could be that engagement in activities at an institutional level have an impact on the relationships ADs have to their colleagues (Solbrekke \& Fremstad, 2018; Stensaker, 2018), and our example shows why and how this might play out in practice. Moving the boundaries of the practice comes with opportunities for development and growth. The task is to be vigilant and sensitive to how trade-offs in such a process manifest for a particular CTL and its members, so that choices of engagement in new activities also become conscious efforts towards discovering possible challenges.

\section{ACKNOWLEDGEMENTS}

The authors would like to thank the HEDWORK research group, University of Oslo, for helpful comments on earlier drafts.

\section{REFERENCES}

Braun, V., \& Clarke, V. (2006). Using thematic analysis in psychology. Qualitative Research in Psychology, 3(2), 77-101.

Farnsworth, V., Kleanthous, I., \& Wenger-Trayner, E. (2016). Communities of practice as a social theory of learning: A conversation with Etienne Wenger. British Journal of Educational Studies, 64(2), 139-160.

Gosling, D. (1996). What do UK educational development units do? International Journal for Academic Development, 1(1), 75-83.

Havnes, A., \& Stensaker, B. (2006). Educational development centres: From educational to organisational development? Quality Assurance in Education, 14(1), 7-20.

Sfard, A., \& Prusak, A. (2005). Telling identities: In search of an analytic tool for investigating learning as a culturally shaped activity. Educational Researcher, 34(4), s. 14-22.

Solbrekke, T. D., \& Fremstad, E. (2018). Universitets- og høgskolepedagogers profesjonelle ansvar. Uniped, 41(3), 229-245.

Solbrekke, T., Sugrue, C., \& Sutphen, M. (2020). Leading in a web of commitments - Negotiating legitimate compromises. In T. Solbrekke, \& C. Sugrue (Eds.), Leading higher education as and for public good: Rekindling education as praxis (pp. 53-69). Routledge.

Stensaker, B. (2018). Universitets- og høyskolepedagogikk i lys av historiske og internasjonale utviklingstrekk. Uniped, 41(03), 206-216.

Stensaker, B., van der Vaart, R., Solbrekke, T. D., \& Wittek, L. (2017). The expansion of academic development: The challenges of organizational coordination and collaboration. In B. Stensaker, 
G. Bilbow, L. Breslow, \& R. van der Vaart (Eds.), Strengthening teaching and learning in research universities (pp. 19-41). Palgrave Macmillan.

Sugrue, C., Englund, T., Solbrekke, T. D., \& Fossland, T. (2018). Trends in the practices of academic developers: Trajectories of higher education? Studies in Higher Education, 43(12), 2336-2353.

Wenger, E. (1998). Communities of practice: Learning, meaning, and identity. Cambridge: University Press.

Wenger, E. (2000). Communities of practice and social learning systems. Organization, 7(2), 225-246.

Open Access. This is an open-access article distributed under the terms of the Creative Commons Attribution-NonCommercial 4.0 International License (https://creativecommons.org/licenses/by-nc/4.0/), which permits unrestricted use, distribution, and reproduction in any medium for non-commercial purposes, provided the original author and source are credited, a link to the CC License is provided, and changes - if any - are indicated. 